\title{
Qualidade do café natural e despolpado após diferentes tipos de secagem e armazenamento ${ }^{1}$
}

\author{
Paulo C. Coradi ${ }^{2}$, Flávio M. Borém ${ }^{3}$ \& João A. Oliveira ${ }^{4}$
}

\section{RESUMO}

Para se comparar as alterações na qualidade do café natural e despolpado em condições de umidades relativas de 60 e $80 \%$ e temperatura controlada de $23{ }^{\circ} \mathrm{C}$ aos 90 e 180 dias de armazenamento, realizou-se este trabalho no Departamento de Engenharia e no Pólo de Tecnologia em Pós-Colheita do Café da Universidade Federal de Lavras. A colheita do café, variedade Topázio, foi seletiva, enquanto uma parte foi despolpada e a outra processada de forma natural; no entanto, uma parcela de cada tipo de café foi conduzida para a secagem em terreiro e a outra parcela para secagem com temperaturas de 40 e $60{ }^{\circ} \mathrm{C}$; após a secagem, o café foi armazenado em ambiente hermético mantendo-se constantes as umidades relativas de 60 e $80 \%$. Para avaliação da qualidade foram feitas análises sensoriais, teste de acidez graxa e avaliação quantitativa da cor. Os resultados obtidos no presente trabalho permitem concluir que: a acidez graxa aumenta ao longo do tempo de armazenamento nas condições de 60 e $80 \%$ de umidade relativa; a descoloração do café é mais intensa ao longo do tempo de armazenamento para as condições de $80 \%$ de umidade relativa; aos 180 dias de armazenamento, a análise sensorial do café é menos afetada pela interação secagem, processamento e armazenamento, nas condições de $60 \%$ de umidade relativa.

Palavras-chave: topázio, umidade, temperatura, terreiro

\section{Quality of natural and washed coffee after different types of drying and storage}

\begin{abstract}
For comparing the alterations in the quality of natural and washed coffee under 60 to $80 \%$ relative humidity conditions from and controlled temperature of $23^{\circ} \mathrm{C}$ at 90 and 180 days of storage, this work was accomplished in the Engineering Department and Coffee Post-Harvest Technology Centre of the Federal University of Lavras. The harvest of coffee, variety Topazio was selective, while a part of the coffee was pulped and the rest processed in the dry method. However, a part of each type of coffee was ground dried and the rest dried at temperatures of 40 and $60{ }^{\circ} \mathrm{C}$; after drying, the coffee was stored in an air-tight place with controlled air temperature and under different conditions of relative humidity (60 and $80 \%$ ). For quality evaluation, a sensorial analysis, fatty acidity test and color quantity evaluation were done. The results obtained in the present work led to the conclusion that: the fatty acidity increased with storage time at $80 \%$ relative humidity; coffee discoloration was more marked at 60 and $80 \%$ of relative humidity; at 180 days of storage, the sensorial analyses of coffee was less affected by the interaction among drying, processing and storage in the conditions of $60 \%$ relative humidity.
\end{abstract}

Key words: topazio, humidity, temperature, ground

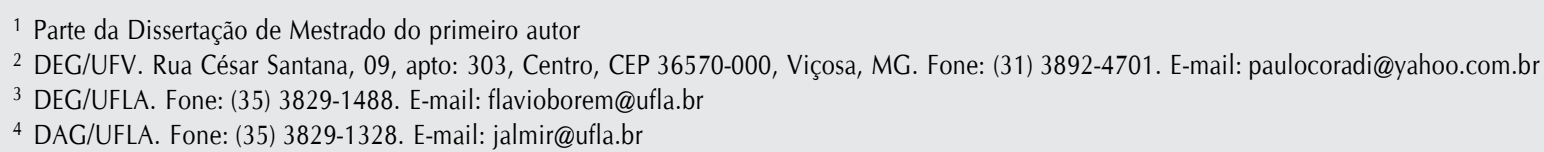




\section{INTRODUÇÃO}

A manutenção da qualidade do café resultante do processamento e da secagem, dependerá das condições de armazenagem, o qual passa a ser uma etapa significativa sob o aspecto de comercialização, tendo em vista que grande parte do café produzido é comercializado em um tempo relativamente curto, causando problemas com transporte e desvalorização do produto.

O equilíbrio entre a oferta e a demanda é muito importante para as expectativas de mercado; esta relação é que determinará os preços para os próximos anos. Observandose dados fornecidos pela USDA (2006), nos últimos cinco anos (2000/01 a 2005/06) concluiu-se que a relação estoque/ consumo de café foi superior a $50 \%$, significando que a demanda de produto foi inferior à oferta, o que acaba abaixando os preços para os anos seguintes e aumentando os estoques de produto.

Para que o café passe a ser ofertado durante um longo período, mantendo-se a elevada qualidade inicial, é conveniente se conhecer as alterações que ocorrem durante o armazenamento sob diferentes condições ambientais e, assim, determinar o controle necessário para sua adequada preservação.

Observou-se, em alguns estudos envolvendo a qualidade do café, que a secagem, quando mal conduzida, compromete a qualidade do produto principalmente quando ele passa a ser armazenado por longos períodos, provocando o decréscimo da qualidade da bebida (Bartholo \& Guimarães, 1997; Leite et al., 1998; Silva et al., 2001; Afonso Júnior, 2001; Nobre, 2005).

Wajda \& Walczyk (1978) e Vidal (2001) estudando a presença dos ácidos graxos (AG) em café durante o armazenamento, observaram que a liberação dos AG não é uniforme e que a degradação se dá de forma diferente de um ácido para outro. Os principais ácidos encontrados no café foram o linoléico e o palmítico e quando observado o seu comportamento ao longo do armazenamento, apresentaram uma maior quantidade com o aumento do tempo de armazenagem e, também, que a condição de armazenamento com temperaturas e umidades mais elevadas provoca maior deterioração da qualidade do café (Afonso Júnior, 2001; Kurzrock et al., 2004).

A acidez graxa faz parte da composição química dos grãos de café que caracteriza a qualidade. Diferenças nos teores de ácidos graxos livres podem ser encontradas em altos níveis, devido às condições de processamento e armazenagem do produto. Esteves (1960) e Jordão et al. (1974) notaram que, sempre que o período de armazenagem do café aumenta, pior é a qualidade do produto e maior a acidez do óleo.

A cor faz parte dos aspectos físicos; ela é uma das características que despertam mais atenção na comercialização, é economicamente importante, uma vez que poderá levar à depreciação do produto e afetar a qualidade da bebida (Mônaco, 1961; Northmore, 1968; Amorim, 1972; Nobre, 2005).

O branqueamento é um fenômeno relevante que ocorre nos grãos de café visto que, através da mudança de cor, o produto poderá perder sua qualidade comercial. As operações de secagem e armazenamento, quando mal conduzidas, são as principais responsáveis pela ocorrência do fenômeno (Antunes \& Sgarbieri, 1979; Melo et al., 1980; Mazzafera et al.,1984; Oliveira, 1995; Leite et al., 1998).

Os grãos de café podem apresentar mudanças de cor durante o período de armazenamento, passando de verde azulado à cor amarelo-claro, fenômeno conhecido como branqueamento, cuja intensidade de ocorrência do fenômeno se dá em função das condições ambientais do local em que o produto se encontra armazenado (Afonso Júnior, 2001).

Para que o café passe a ser ofertado por longo período mantendo a sua elevada qualidade inicial, torna-se necessidade prioritária se conhecer as alterações que ocorrem durante o armazenamento sob diferentes condições ambientais e, assim, determinar o controle necessário para sua adequada preservação.

Considerando-se as poucas informações sobre o efeito do processo de secagem e armazenamento para os diferentes métodos de processamento do café e as dificuldades de determinadas regiões em armazenar o produto, em virtude da elevada umidade relativa e temperatura do ar ambiente, se objetivou, através deste trabalho, comparar as alterações na qualidade do café natural e despolpado, em condições de umidades relativas de 60 e $80 \%$ e temperatura controlada de $23^{\circ} \mathrm{C}$ aos 90 e 180 dias de armazenamento.

\section{MATERIAL E MÉTODOS}

\section{Local da realização do experimento}

O trabalho foi realizado no Departamento de Engenharia e no Pólo de Tecnologia em Pós-Colheita de Café da Universidade Federal de Lavras.

\section{Processamento do café}

O café foi colhido manualmente e de forma seletiva, retirando-se da planta somente os frutos cereja. Colheram-se, para cada bloco, 800 L de café da variedade Topázio. Toda a matéria-prima foi uniformizada através da separação dos cafés verdes, verde-cana, passa e bóia; em seguida, cerca de $150 \mathrm{~L}$ do café cereja foram levados diretamente para o terreiro, constituindo a parcela de café natural. Para obtenção do café despolpado, cerca de 350 L do café cereja foram descascados; depois, $150 \mathrm{~L}$ de café com pergaminho foram colocados em um tanque de fermentação no qual permaneceram durante 20 h; após esse tempo, o café foi lavado para retirada da mucilagem. Tem-se, na Figura 1, o fluxograma dos diferentes tipos de processamento, secagem e armazenamento do café.

\section{Secagem do café}

Após o despolpamento, o café foi para a pré-secagem em terreiro onde permaneceu um dia; o café natural e o café despolpado foram divididos em parcelas distintas no terreiro e, durante o tempo em que o café permaneceu no terreiro, foram realizados revolvimentos de meia em meia hora e monitoramento da temperatura e umidade relativa do ar ambiente, foram realizados por meio de termohigrógrafo. 


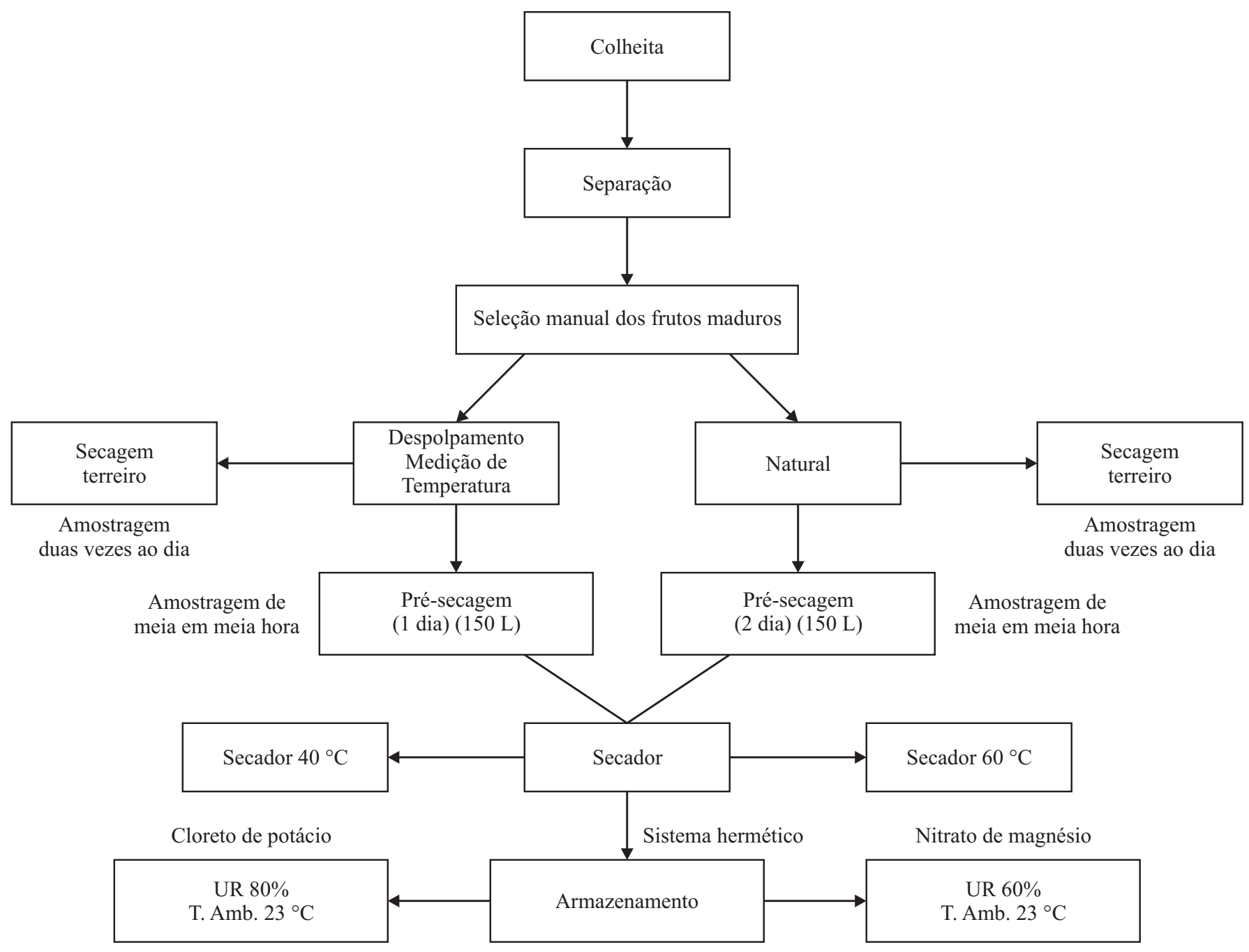

Figura 1. Fluxograma do processamento, secagem e armazenamento do café

A secagem mecânica foi conduzida em dois protótipos de camada fixa com temperaturas, nos secadores, de 40 e $60^{\circ} \mathrm{C}$ em que, para obtenção do fluxo de ar, se utilizou um diafragrama com abertura graduada na entrada do ventilador. A velocidade média do ar foi medida por meio de um anemômetro de pás na entrada da câmara de secagem e o fluxo de ar foi regulado para $20 \mathrm{~m}^{3} \mathrm{~min}^{-1} \mathrm{~m}^{-2}$.

Durante a secagem foram monitorados, periodicamente: a temperatura na massa de café, a temperatura e a umidade relativa do ar ambiente. As temperaturas da massa de café foram medidas a cada $30 \mathrm{~min}$, por meio de termopares tipo J colocados no centro da massa, em cada divisão da câmara de secagem; para minimizar uma possível diferença de temperatura entre as quatro divisões devido à posição das resistências no plenum, fez-se um rodízio das amostras, a cada hora.

As amostras para determinação do teor de água do café em terreiro foram coletadas no final do período da manhã e no final da tarde, durante os cinco primeiros dias e depois diariamente, no final da tarde, enquanto na secagem mecânica foram coletadas amostras para determinação do teor de água, de hora em hora. A determinação do teor de água foi realizada pelo método da estufa a $105 \pm 3{ }^{\circ} \mathrm{C}$ (Brasil, 1992).

\section{Armazenamento do café}

Quando a secagem foi interrompida em 11\% (b.u.) de umidade, o café foi acondicionado em sacos de juta e armazenado em dois contêineres herméticos, com umidades relativas controladas de 60 e $80 \%$. Os contêineres ficaram em ambiente com temperatura controlada de 21 a $23{ }^{\circ} \mathrm{C}$ durante todo o tempo de armazenamento.

Para garantir o controle das umidades relativas (60 e 80\%) foram utilizados dois tipos de sal; nitrato de magnésio (60\% de umidade) e cloreto de potássio (80\% de umidade), específicos para as umidades estabelecidas. $\mathrm{O}$ ar circulou de forma contínua em sistema fechado, ou seja, passava pela massa de grãos e pelos sais, continuamente.

As umidades e temperaturas foram medidas diariamente no turno da manhã, durante os seis meses de armazenamento e, para medir e controlar os sistemas de armazenamento (umidades e temperaturas) utilizou-se um aparelho digital Higrotemp 90.

\section{Análise sensorial}

A análise sensorial do café foi realizada na Fazenda Monte Alegre S/A de Alfenas, MG, para cuja realização se retirararam os defeitos de $300 \mathrm{~g}$ de amostra de café, que 
foram analisadas por três provadores especializados da BSCA (Brazil Specialty Coffee Association), os quais receberam todas as amostras codificadas.

A metodologia utilizada foi a do CoE ("Cup of Excellence”), de 1997, indicada por George Howell, na qual cada atributo sensorial (corpo, aroma, acidez, doçura, balanço, bebida limpa, sabor característico) recebeu uma nota, de acordo com cada tipo de amostra, sendo por isto mais objetiva que a prova de xícara. As amostras receberam notas de 0 a 8 para cada atributo sensorial, em uma escala de pontos (BSCA, 2005).

Através dessa escala, os degustadores avaliaram o aroma do café em três partes: pó seco, crosta e infusão e anotaram, em um espaço reservado para observações pessoais, as nuances e aromas diferenciados; em seguida, avaliaram-se os atributos de bebida limpa, doçura, acidez, corpo, sabor, sabor remanescente, balanço ou equilíbrio e nota geral, resultando em uma contagem de pontos através da qual eram indicados os cafés de melhor qualidade.

\section{Acidez graxa}

A acidez graxa foi determinada por titulação, de acordo com o método 02 - 02 A (método rápido de acidez graxa, descrito na AACC (1995)); 40 g da amostra de café moído foram pesados e adicionados $100 \mathrm{~mL}$ de tolueno, agitandose a mistura durante 1 h e 30 min; logo depois, realizou-se a filtragem com papel de filtro e se misturaram em um beker, $25 \mathrm{~mL}$ da solução filtrada e $25 \mathrm{~mL}$ de álcool mais fenolftaleína e depois titulou-se a solução com KOH até atingir o ponto de viragem. O resultado da acidez graxa foi expresso em mL de $\mathrm{KOH}$, por $100 \mathrm{~g}$ de MS, calculado de acordo com as Eq. 1 e 2.

$$
\mathrm{PS}=(1-\mathrm{U}) \times 40
$$

em que:

$$
\begin{aligned}
& \text { PS - peso da amostra seca, g } \\
& \text { U - umidade, \% de base úmida }
\end{aligned}
$$

$$
\mathrm{AG}=\frac{\mathrm{V} \times 100}{\mathrm{PS}}
$$

em que:

$$
\begin{gathered}
\mathrm{V} \text { - volume gasto de } \mathrm{KOH} \text { na titulação da mistura } \\
\text { (extrato + indicador), } \mathrm{mL} \\
\mathrm{AG} \text { - acidez graxa, } \mathrm{mL} \text { de } \mathrm{KOH} \text { por } 100 \mathrm{~g} \text { de } \mathrm{MS}
\end{gathered}
$$

\section{Avaliação da cor}

A cor das amostras foi determinada utilizando-se colorímetro MINOLTA modelo CR 300, por leitura direta das coordenadas L, a e b, descritas por Nobre (2005). A coordenada L mede a luminosidade (cores escuras e claras), a coordenada a mede a cromaticidade (cores esverdeada e avermelhada) e a coordenada b mede a saturação (cores azulada e amarelada). As amostras foram colocadas em placas de Petri e, para cada repetição, se realizaram cinco leituras nos quatro pontos cardeais e uma no ponto central da placa.

\section{Tratamento e delineamento experimental}

O delineamento utilizado foi o DIC (Delineamento Inteiramente Casualizado), em esquema fatorial ( $2 \times 3 \times 2)$, com três repetições, sendo os tratamentos dois tipos de café (natural e despolpado), três sistemas de secagem (terreiro, temperatura $40^{\circ} \mathrm{C}$ e temperatura $60^{\circ} \mathrm{C}$ ) e duas condições de armazenamento com umidades relativas de 60 e $80 \%$.

Os dados obtidos foram analisados pelo programa computacional Sisvar 4.0 (Ferreira, 2000) com as médias pelo teste de Tukey.

\section{RESULTADOS E DISCUSSÃO}

Os valores médios da temperatura e umidade relativa do ar ambiente, na entrada do secador e os teores de água inicial e final do café em terreiro e com ar aquecido 40 e $60{ }^{\circ} \mathrm{C}$, para cada tratamento e nas três repetições, são apresentados na Tabela 1.

Os valores da temperatura e da umidade relativa do ar de entrada do secador referem-se aos valores médios diários coletados durante a secagem mecânica, com ar aquecido de 40 e $60{ }^{\circ} \mathrm{C}$ na massa de café. Observa-se, na Tabela 1 , que os dados das umidades relativas e temperaturas do ar médias foram semelhantes para todos os testes, variando de 49 a $61 \%$ (b.u.) e de 20,23 a $23,43{ }^{\circ} \mathrm{C}$, respectivamente. Para a secagem em terreiro, a temperatura e a umidade relativa do ar ambiente foram de 20,53 a $24,1^{\circ} \mathrm{C}$ e 46 a $66 \%$ (b.u.), respectivamente, para todas as repetições.

Nota-se, na Tabela 1, que o teor de água inicial do café despolpado variou de 50,78 a 57,66\% (b.u.) e, após a secagem em terreiro, o teor de água foi de 10,15\% (b.u.). Para o café natural se observaram, no início da secagem, teores de água na faixa de 58,60 a 65,60\% (b.u.), chegando à umidade média de armazenamento com teores de água de $12 \%$ (b.u.).

Antes que o café passasse por uma secagem com ar aquecido a 40 e $60{ }^{\circ} \mathrm{C}$ fez-se uma pré-secagem de um dia, em terreiro para o café despolpado e, dois dias, para o natural, a fim de que os dois tipos de café entrassem na secagem mecânica nas mesmas condições ambientais perdendo, em média, cinco pontos percentuais de teor de água. Observouse que o café natural iniciou a secagem no secador com teor de água variando de 43,08 a 50,95\% (b.u.), alcançando o teor de água médio de armazenamento com 11,03\% (b.u.), enquanto o café despolpado iniciou com teores de água na faixa de 38,71 a $40,42 \%$ (b.u.), chegando ao teor de água médio de armazenamento com 10,56\% (b.u.).

Durante o tempo de armazenamento as temperaturas ficaram entre 21,8 e $22,8^{\circ} \mathrm{C}$, com variação média de $1^{\circ} \mathrm{C}$; por outro lado, as umidades relativas nas condições de armazenamento se mantiveram na faixa de 63,8 a $64,6 \%$, para a condição de $60 \%$ de umidade relativa, e 84,6 a 85,4\%, para a condição de $80 \%$ de umidade relativa; esses valores concordam com os resultados obtidos por Afonso Júnior (2001) que avaliou o teor de água de equilíbrio dos cafés cereja, descascado, despolpado e beneficiado.

Apresentam-se, na Figura 2 os valores médios do teor de 
Tabela 1. Valores médios das condições do produto e do ar ambiente para os tratamentos, nas três repetições

\begin{tabular}{|c|c|c|c|c|c|c|c|}
\hline \multirow[t]{2}{*}{ Repetição } & \multirow[t]{2}{*}{ Café } & \multirow{2}{*}{$\begin{array}{l}\text { Temperatura } \\
\text { da massa }\left({ }^{\circ} \mathrm{C}\right)\end{array}$} & \multirow{2}{*}{$\begin{array}{l}\text { Fluxo de ar } \\
\left(\mathrm{m}^{3} \mathrm{~min}^{-1} \mathrm{~m}^{2}\right)\end{array}$} & \multicolumn{2}{|c|}{ Teor de água (\%) b.u. } & \multicolumn{2}{|c|}{$\begin{array}{l}\text { Condições médias do ar na entrada } \\
\text { do secador e terreiro }\end{array}$} \\
\hline & & & & Início & Final & Temperatura $\left({ }^{\circ} \mathrm{C}\right)$ & UR (\%) \\
\hline \multirow{6}{*}{ I } & Despolpado & 60 & 20 & 41,34 & 11,35 & 20,76 & 61 \\
\hline & Natural & 60 & 20 & 50,11 & 11,15 & 20,76 & 61 \\
\hline & Despolpado & 40 & 20 & 41,34 & 12,00 & 20,23 & 59 \\
\hline & Natural & 40 & 20 & 50,95 & 12,22 & 20,23 & 59 \\
\hline & Despolpado & - & terreiro & 50,78 & 9,33 & 24,10 & 46 \\
\hline & Natural & - & terreiro & 61,38 & 11,79 & 23,51 & 50 \\
\hline \multirow{6}{*}{ II } & Despolpado & 60 & 20 & 40,12 & 9,33 & 21,54 & 55 \\
\hline & Natural & 60 & 20 & 43,08 & 9,49 & 21,54 & 55 \\
\hline & Despolpado & 40 & 20 & 38,71 & 11,12 & 21,89 & 54 \\
\hline & Natural & 40 & 20 & 43,87 & 12,22 & 21,89 & 54 \\
\hline & Despolpado & - & terreiro & 51,97 & 10,74 & 21,34 & 57 \\
\hline & Natural & - & terreiro & 58,60 & 12,94 & 22,42 & 56 \\
\hline \multirow{6}{*}{ III } & Despolpado & 60 & 20 & 41,76 & 9,12 & 23,22 & 49 \\
\hline & Natural & 60 & 20 & 45,72 & 11,81 & 23,22 & 49 \\
\hline & Despolpado & 40 & 20 & 40,42 & 11,27 & 23,43 & 51 \\
\hline & Natural & 40 & 20 & 46,07 & 12,57 & 23,43 & 51 \\
\hline & Despolpado & - & terreiro & 57,66 & 11,04 & 20,53 & 66 \\
\hline & Natural & - & terreiro & 65,60 & 11,65 & 21,50 & 58 \\
\hline
\end{tabular}

água do café armazenado sob as condições controladas de 60 e $80 \%$ de umidade relativa.

Nota-se, na Figura 2, que os teores de água dos grãos de café variaram durante o tempo de armazenamento para as condições de $80 \%$ de umidade relativa e, ainda que, ao determinar o teor de água aos 90 dias de armazenamento, já havia entrado em equilíbrio com a umidade relativa do ar aumentando em média o teor de água de $11 \%$ para 19\%, nas condições de $80 \%$ de umidade relativa, de acordo com os modelos de equilíbrio higroscópico descritos por Afonso Júnior (2001), para todos os tratamentos; no entanto, para as condições de umidade relativa de $60 \%$, o café se manteve com as umidades iniciais de equilíbrio até o final de arma- zenamento. Conforme Vilela et al. (2000) o aumento do teor de água nos grãos durante o armazenamento proporciona alterações negativas na composição físico-química dos grãos, prejudicando a qualidade do café.

A Tabela 2 apresenta os valores médios de acidez graxa para o café natural e despolpado, em função dos tipos de secagem, e condições de armazenamento aos 90 dias.

Observa-se, na Tabela 2, que os valores médios de acidez graxa aumentaram significativamente com o aumento da umidade relativa de armazenamento, para $80 \%$ aos 90 dias. Os pesquisadores Afonso Júnior (2001) e Kurzrock et al. (2004) ao estudarem o armazenamento na qualidade do café, concluíram que, na medida em que o

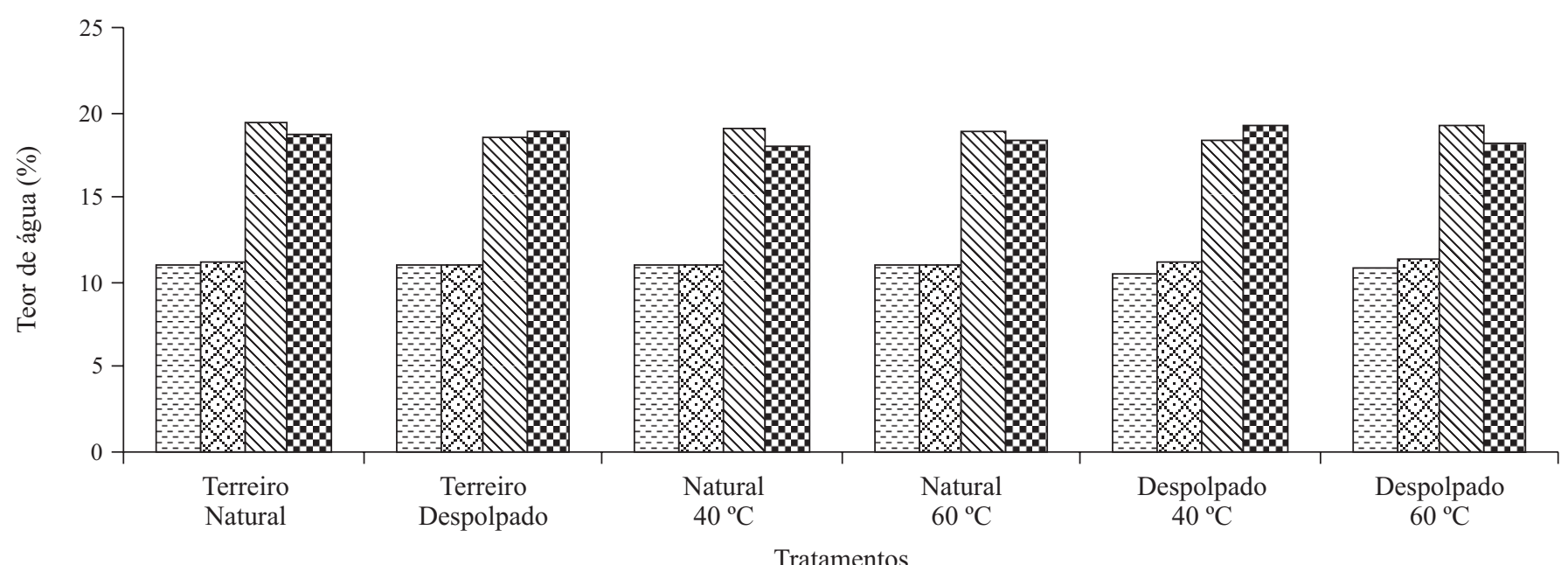
Armazenamento 90 dias $/ 60 \%$
ج. Armazenamento 180 dias $/ 60 \%$
Armazenamento 90 dias/80\%
A Armazenamento 180 dias $/ 80 \%$

Figura 2. Valores médios de teor de água do café armazenado durante os 90 e 180 dias, nas condições controladas de 60 e $80 \%$ de umidade relativa, para todos os tratamentos 
Tabela 2. Valores médios de acidez graxa $(\mathrm{KOH} \mathrm{0,1} \mathrm{N/100} \mathrm{g),} \mathrm{durante}$ o tempo de 90 dias de armazenamento, em função dos tipos de secagem e condições de umidade relativa de armazenamento

\begin{tabular}{ccc}
\hline Tipos de secagem & \multicolumn{2}{c}{ Umidade relativa de armazenamento } \\
\cline { 2 - 3 } & $\mathbf{6 0 \%}$ & $\mathbf{8 0} \%$ \\
Terreiro & $1,37 \mathrm{Aa}$ & $1,85 \mathrm{Ab}$ \\
$40^{\circ} \mathrm{C}$ & $1,57 \mathrm{Aa}$ & $1,95 \mathrm{Ab}$ \\
$60^{\circ} \mathrm{C}$ & $2,27 \mathrm{Ba}$ & $2,15 \mathrm{Ba}$ \\
\hline
\end{tabular}

Médias seguidas da mesma letra minúscula na linha e maiúsculas nas colunas não diferem, a 1\% de probabilidade, pelo teste de Tukey

período de armazenagem do café aumenta, pior é a qualidade do produto e maior a acidez do óleo devido, sobretudo, às elevadas temperaturas e umidades relativas do armazenamento, porém, observando-se os tipos de secagem (Tabela 3), os maiores valores de acidez graxa foram verificados para a temperatura de $60{ }^{\circ} \mathrm{C}$ e, quando comparados com os efeitos do armazenamento de 60 e $80 \%$ de umidade relativa, não se consegue perceber diferença significativa entre os tratamentos. Marques (2006) nota que as elevadas temperaturas de secagem rompem as estruturas das membranas celulares, provocando o extravasamento dos óleos e comprometendo a qualidade do café com os processos de oxidação.

Os valores médios das coordenadas de cor ( $\mathrm{L}, \mathrm{a}, \mathrm{b}) \mathrm{du}-$ rante o tempo de 90 e 180 dias de armazenamento, em função dos diferentes tipos de secagem, processamentos e condições de armazenamento, estão apresentados nas Tabelas 3, 4,5 e 6.

Tabela 3. Valores médios das coordenadas de cor (L) e (a), durante 0 tempo de 90 dias de armazenamento, em função dos tipos de secagem e condições de armazenamento

\begin{tabular}{ccccccc}
\hline \multirow{2}{*}{$\begin{array}{c}\text { Tipos de } \\
\text { secagem }\end{array}$} & \multicolumn{2}{c}{$\begin{array}{c}\text { Umidade relativa de } \\
\text { armazenamento cor (L) }\end{array}$} & & \multicolumn{2}{c}{$\begin{array}{c}\text { Umidade relativa de } \\
\text { armazenamento cor (a) }\end{array}$} \\
\cline { 2 - 3 } \cline { 5 - 7 } & $\mathbf{6 0 \%}$ & $\mathbf{8 0 \%}$ & & $\mathbf{6 0 \%}$ & $\mathbf{8 0 \%}$ \\
Terreiro & $45,03 \mathrm{Aa}$ & $46,20 \mathrm{Ab}$ & & $0,93 \mathrm{Aa}$ & $1,30 \mathrm{Ab}$ \\
$40^{\circ} \mathrm{C}$ & $45,33 \mathrm{Aa}$ & $46,80 \mathrm{Ab}$ & & $1,17 \mathrm{Aa}$ & $1,26 \mathrm{Ab}$ \\
$60^{\circ} \mathrm{C}$ & $46,47 \mathrm{Ba}$ & $47,73 \mathrm{Bb}$ & & $1,17 \mathrm{Aa}$ & $1,47 \mathrm{Ab}$ \\
\hline
\end{tabular}

Médias seguidas da mesma letra e maiúsculas nas colunas, não diferem, a 5\% de probabilidade, pelo teste de Tukey

Tabela 4. Valores médios da coordenada de cor (L) e (b) durante 0 tempo de 180 dias de armazenamento, em função dos tipos de secagem e condições de umidade relativa de armazenamento, para 0 café natural e despolpado

\begin{tabular}{|c|c|c|c|c|}
\hline \multirow{2}{*}{$\begin{array}{l}\text { Tipos de } \\
\text { Secagem }\end{array}$} & \multicolumn{2}{|c|}{ Natural } & \multicolumn{2}{|c|}{ Despolpado } \\
\hline & $60 \%$ & $80 \%$ & $60 \%$ & $80 \%$ \\
\hline & \multicolumn{4}{|c|}{ Cor $(\mathrm{L})$} \\
\hline Terreiro & $47,51 \mathrm{Aa}$ & $51,50 \mathrm{Ab}$ & $46,72 \mathrm{Aa}$ & $53,89 \mathrm{Bb}$ \\
\hline $40^{\circ} \mathrm{C}$ & $48,44 \mathrm{Aa}$ & $52,40 \mathrm{Ab}$ & $47,76 \mathrm{Aa}$ & $50,01 \mathrm{Ab}$ \\
\hline \multirow[t]{2}{*}{$60^{\circ} \mathrm{C}$} & $52,31 \mathrm{Ba}$ & $55,63 \mathrm{Bb}$ & $50,97 \mathrm{Ba}$ & $57,19 \mathrm{Cb}$ \\
\hline & \multicolumn{4}{|c|}{ Cor (b) } \\
\hline Terreiro & $11,30 \mathrm{Aa}$ & $16,09 \mathrm{Ab}$ & $9,67 \mathrm{Aa}$ & $13,13 \mathrm{Ab}$ \\
\hline $40^{\circ} \mathrm{C}$ & $12,55 \mathrm{Aa}$ & $16,01 \mathrm{Ab}$ & $10,67 \mathrm{Ba}$ & $13,90 \mathrm{Ab}$ \\
\hline $60^{\circ} \mathrm{C}$ & $12,60 \mathrm{Aa}$ & $15,60 \mathrm{Ab}$ & $10,61 \mathrm{Ba}$ & $13,65 \mathrm{Ab}$ \\
\hline
\end{tabular}

Médias seguidas da mesma letra minúscula na linha e maiúsculas nas colunas, não diferem, a

$1 \%$ de probabilidade, pelo teste de Tukey
Tabela 5. Valores médios da coordenada de cor (a), durante o tempo de 90 e 180 dias de armazenamento, em função dos tipos de processamento e condições de armazenamento

\begin{tabular}{ccccccc}
\hline \multirow{2}{*}{$\begin{array}{c}\text { Tipos de } \\
\text { processamento }\end{array}$} & \multicolumn{2}{c}{$\begin{array}{c}\text { Umidade relativa de } \\
\text { armazenamento (90 dias) }\end{array}$} & & \multicolumn{2}{c}{$\begin{array}{c}\text { Umidade relativa de } \\
\text { armazenamento (180 dias) }\end{array}$} \\
\cline { 2 - 3 } \cline { 6 - 7 } Natural & $\mathbf{6 0} \%$ & $\mathbf{8 0} \%$ & & $\mathbf{6 0 \%}$ & $\mathbf{8 0 \%}$ \\
Despolpado & $1,47 \mathrm{Ba}$ & $1,40 \mathrm{Ba}$ & & $1,80 \mathrm{Ba}$ & $1,87 \mathrm{Ba}$ \\
\cline { 6 - 7 } & $1,22 \mathrm{Ab}$ & $0,78 \mathrm{Aa}$ & & $1,31 \mathrm{Ab}$ & $1,03 \mathrm{Aa}$ \\
\hline
\end{tabular}

Médias seguidas da mesma letra minúscula na linha e maiúsculas nas colunas, não diferem, a $5 \%$ de probabilidade, pelo teste de Tukey

Tabela 6. Valores médios da coordenada de cor (b), durante o tempo de 90 dias de armazenamento, em função dos tipos de secagem e condições de armazenamento

\begin{tabular}{ccc}
\hline Tipos de secagem & \multicolumn{2}{c}{ Umidade relativa de armazenamento } \\
\cline { 2 - 3 } & $\mathbf{6 0 \%}$ & $\mathbf{8 0 \%}$ \\
Terreiro & $11,13 \mathrm{Aa}$ & $13,27 \mathrm{Ab}$ \\
$40^{\circ} \mathrm{C}$ & $11,50 \mathrm{ABa}$ & $13,40 \mathrm{Ab}$ \\
$60^{\circ} \mathrm{C}$ & $12,17 \mathrm{Ba}$ & $12,67 \mathrm{Ab}$ \\
\hline
\end{tabular}

Médias seguidas da mesma letra, minúscula na linha e maiúsculas nas colunas, não diferem a $5 \%$ de probabilidade, pelo teste de Tukey

Verifica-se, nas Tabelas 3, 4, 5 e 6, que os valores das coordenadas (L, a, b), aos 90 e 180 dias de armazenamento, aumentaram significativamente nas condições de $80 \%$ de umidade relativa, independente dos tipos de secagem e processamento. Silva (2001) observou as maiores mudanças na coloração do café quando armazenado nas condições superiores a $80 \%$ de umidade relativa, enquanto Vilela et al. (2000) notaram alterações na cor dos grãos quando armazenados em ambientes com umidades relativas de 75 a $85 \%$.

Observando-se os tipos de secagem e processamento (Tabelas $3,4,5$ e 6 ), a temperatura de $60{ }^{\circ} \mathrm{C}$ e o café natural apresentaram, respectivamente, os maiores valores de luminosidade (L) e cromaticidade (a), caracterizando os grãos de café secados a $60^{\circ} \mathrm{C}$ como de pior qualidade quando comparados com a secagem em terreiro e temperatura de $40^{\circ} \mathrm{C}$. De acordo com Silva (2001), Afonso Júnior (2001) e Corrêa et al. (2002) a secagem altera a cor dos grãos de café, especialmente nos secadores mecânicos. A utilização de temperaturas superiores a $80{ }^{\circ} \mathrm{C}$ favorece o surgimento de grãos de cor amarelada em que, ao reabsorverem umidade, as temperaturas provocam o branqueamento irregular; por outro lado, a secagem em terreiro, em virtude de utilizar apenas temperaturas ambientes (baixas) não afeta as características da cor dos grãos, quando comparados com as do café de secador.

Apresenta-se, na Tabela 7, os valores médios da análise sensorial para o café natural e despolpado, em função dos tipos de secagem e das diferentes condições de armazenamento.

Tem-se, na Tabela 7, que aos 90 dias de armazenamento os efeitos das condições de armazenagem sobre a análise sensorial, ocorreram somente para temperatura de $60^{\circ} \mathrm{C}$, apresentando os melhores valores para umidade relativa de $60 \%$.

No armazenamento de 180 dias (Tabela 7), verifica-se que as melhores notas de análise sensorial foram encontradas 
Tabela 7. Valores médios de análise sensorial (\%), durante o tempo de 90 e 180 dias de armazenamento, em função dos tipos de secagem e condições de armazenamento, para o café natural e despolpado

\begin{tabular}{cccccc}
\hline Tipos de & \multicolumn{2}{c}{ Natural } & & \multicolumn{2}{c}{ Despolpado } \\
\cline { 2 - 4 } \cline { 5 - 6 } Secagem & $\mathbf{6 0 \%}$ & $\mathbf{8 0 \%}$ & & $\mathbf{6 0 \%}$ & $\mathbf{8 0} \%$ \\
\hline \multirow{3}{*}{ Terreiro } & $78,33 \mathrm{Aa}$ & $78,11 \mathrm{Ba}$ & & $80,33 \mathrm{Aa}$ & $80,67 \mathrm{Ba}$ \\
$40^{\circ} \mathrm{C}$ & $78,11 \mathrm{Aa}$ & $76,33 \mathrm{ABa}$ & & $80,22 \mathrm{Aa}$ & $79,78 \mathrm{ABa}$ \\
$60^{\circ} \mathrm{C}$ & $78,00 \mathrm{Ab}$ & $74,00 \mathrm{Aa}$ & & $81,00 \mathrm{Ab}$ & $78,78 \mathrm{Aa}$ \\
\hline \multicolumn{5}{c}{ Armazenamento durante 180 dias } \\
Terreiro & $74,11 \mathrm{Ab}$ & $70,56 \mathrm{Ba}$ & & $80,89 \mathrm{Bb}$ & $77,22 \mathrm{Ba}$ \\
$40^{\circ} \mathrm{C}$ & $73,44 \mathrm{Ab}$ & $70,78 \mathrm{Ba}$ & & $77,44 \mathrm{Ab}$ & $74,33 \mathrm{Aa}$ \\
$60^{\circ} \mathrm{C}$ & $74,78 \mathrm{Ab}$ & $68,11 \mathrm{Aa}$ & & $78,00 \mathrm{Ab}$ & $73,67 \mathrm{Aa}$ \\
\hline
\end{tabular}

Médias seguidas da mesma letra, minúscula na linha e maiúsculas nas colunas, não diferem, a $1 \%$ de probabilidade, pelo teste de Tukey

para as condições de $60 \%$ de umidade relativa, independente dos tipos de secagem e processamento.

Os tipos de secagem para os 90 e 180 dias de armazenamento apresentaram influência significativa nos valores médios da análise sensorial nas condições de $80 \%$ de umidade relativa, apresentando as melhores notas para a secagem em terreiro.

\section{CONCLUSÕES}

1. A acidez graxa aumenta ao longo do tempo de armazenamento, nas condições de 60 e $80 \%$ de umidade relativa.

2. A descoloração do café é mais intensa ao longo do tempo de armazenamento para as condições de $80 \%$ de umidade relativa.

3. Aos 180 dias de armazenamento a análise sensorial do café é menos afetada pela interação secagem, processamento e armazenamento nas condições de $60 \%$ de umidade relativa.

\section{AGRADECIMENTOS}

Os autores agradecem à FAPEMIG e ao CNPq pelo apoio financeiro necessário à realização deste trabalho.

\section{LITERATURA CITADA}

AACC - American Association of Cereal Chemists. Methods 0202A: Fat acidity - rapid method, for grain. In: Approved methods of the American Association of the Cereal Chemists. St. Paul: AACC, 1995. v.1, paginação irregular

Afonso Júnior, P. C. Aspectos físicos, fisiológicos e da qualidade do café em função da secagem e do armazenamento. Viçosa: UFV, 2001. 373 p. Tese Doutorado

Amorim, H. V. Relação entre alguns compostos orgânicos de grão de café verde com a qualidade da bebida. Piracicaba: ESALQ, 1972. 136p. Tese Doutorado
Antunes, P.; Sgarbieri, V. C. Influence of time and conditions of storage on technological and nutricional properties of a dry bean (Phaseolus vulgaris L.) variety rosinha G2. Journal of Food Science, v.44, n.10, p.1704, 1979.

Bartholo, G. F.; Guimarães, P. T. G. Cuidados na colheita e preparo do café. Informe Agropecuário, v.18, n.187, p.33-42, 1997.

Brasil. Ministério da Agricultura e Reforma Agrária. Regras para análise de sementes. Brasília, 1992. 356p.

BSCA - Associação Brasileira de Cafés Especiais. Cafés especiais. http://www.bsca.com.br. 25 Jan. 2005.

Corrêa, P. C.; Afonso Júnior, P. C.; Pinto, F. A. C. Efeito da temperatura de secagem na cor dos grãos de café pré-processado por "via seca” e "via úmida”. Revista Brasileira de Armazenamento, v. especial, n.5, p.22-27, 2002.

Esteves, A. B. Acidificação, ao longo do tempo da gordura do grão de café cru. Estudos Agronômicos, v.1, n.4, p.297-317, 1960.

Ferreira, D. F. Análises estatísticas por meio do Sisvar para Windows versão 4.0. In: Reunião Anual da Região Brasileira da Sociedade Internacional de Biometria, 45, 2000, São Carlos. Anais... São Carlos: UFSCar, 2000. p 255-258.

Jordão, B. A.; Garrut, R. S.; Angelucci, E.; Tango, J. S.; Toselo, Y. Armazenamento de café a granel em silo com ventilação natural. In: Congresso Brasileiro de Pesquisas Cafeeiras, 2, 1974, Poços de Caldas. Anais.... Poços de Caldas: MIC-IBC, 1974. p.385.

Kurzrock, T.; Kolling-Speer, I.; Speer, K. Effects of controlled storage on the lipid fraction of green Arabica Coffee Beans. Food Chemistry, v.66, p.161-168, 2004.

Leite, R. A.; Corrêa, P. C.; Oliveira, M. G. A.; Reis, F. P.; Oliveira, T. T. Qualidade tecnológica do café (Coffea arabica L.) préprocessado por “via seca” e "via úmida” avaliada por método químico. Revista Brasileira de Engenharia Agrícola e Ambiental, v.2, n.3, p.308-311, 1998.

Marques, E. R. Alterações químicas, sensoriais e microscópicas dos grãos de café cereja e descascado submetidos a diferentes taxas de remoção de água. Lavras: UFLA, 2006, Dissertação Mestrado

Mazzafera, P.; Guerreiro, F. O.; Carvalho, A. Estudo de coloração verde do grão de café: Determinação de flavonóides e clorofilas. In: Congresso Brasileiro de Pesquisas Cafeeiras, 11, 1984, Londrina. Anais... Rio de Janeiro: MIC/IBC, 1984. p.178-181.

Melo, M.; Fazuoli, L. C.; Teixeira, A. A.; Amorim, H. V. Alterações físicas, químicas e organolépticas em grãos de café armazenados. Ciência e Cultura, v.32, n.4, p.468-471, 1980.

Mônaco, L. C. Armazenamento de café. Boletim da Superintendência dos Serviços do Café. v.36, n.417, p.15-16, 1961.

Nobre, G. W. Alterações qualitativas do café cereja descascado durante o armazenamento. Lavras: UFLA, 2005. 124p. Dissertação Mestrado

Northmore, J. M. Some factors affecting the quality of Kenya coffee. Turrialba, v.15, n.3, p.184-192, 1968.

Oliveira, M. V. Efeito do armazenamento no branqueamento de grãos de café beneficiado: Modelagem matemática do processo. Lavras: UFLA, 1995. 99p. Dissertação Mestrado

Silva, R. P. G.; Vilela, E. R.; Pereira, R. G. F. A.; Borém, F. M. Qualidade de grãos de café (Coffea arábica L.) armazenados em coco com diferentes níveis de umidade. Revista Brasileira de Armazenamento, v. especial, n.3, p.3-10, 2001.

R. Bras. Eng. Agríc. Ambiental, v.12, n.2, p.181-188, 2008. 
USDA - Departamento de Agricultura dos Estados Unidos. Produção mundial de café (mil sacas de $60 \mathrm{~kg}$ ). Anuário da Agricultura Brasileira, São Paulo: FNP Consultoria e Comércio, 2006, p.209-223

Vidal, H. M. Composição lipídica e a qualidade do café (coffea arábica L.) durante armazenamento. Viçosa: UFV, 2001, 93p. Dissertação Mestrado
Vilela, E. R.; Chandra, P. K.; Oliveira, G. A. Efeito da temperatura e umidade relativa no branqueamento de grãos de café. Revista Brasileira de Armazenamento, v. especial, n.1, p.31-37, 2000.

Wajda, P.; Walczyk, D. Relationship between acid value of extracted fatty matter and age of green coffee bean. Journal Science Food Agricultural, v.29, n.7, p.377-380, 1978. 